\title{
Sem corpo, sem problemas Narradores e contadores de histórias
}

\section{Rui Pina Coelho}

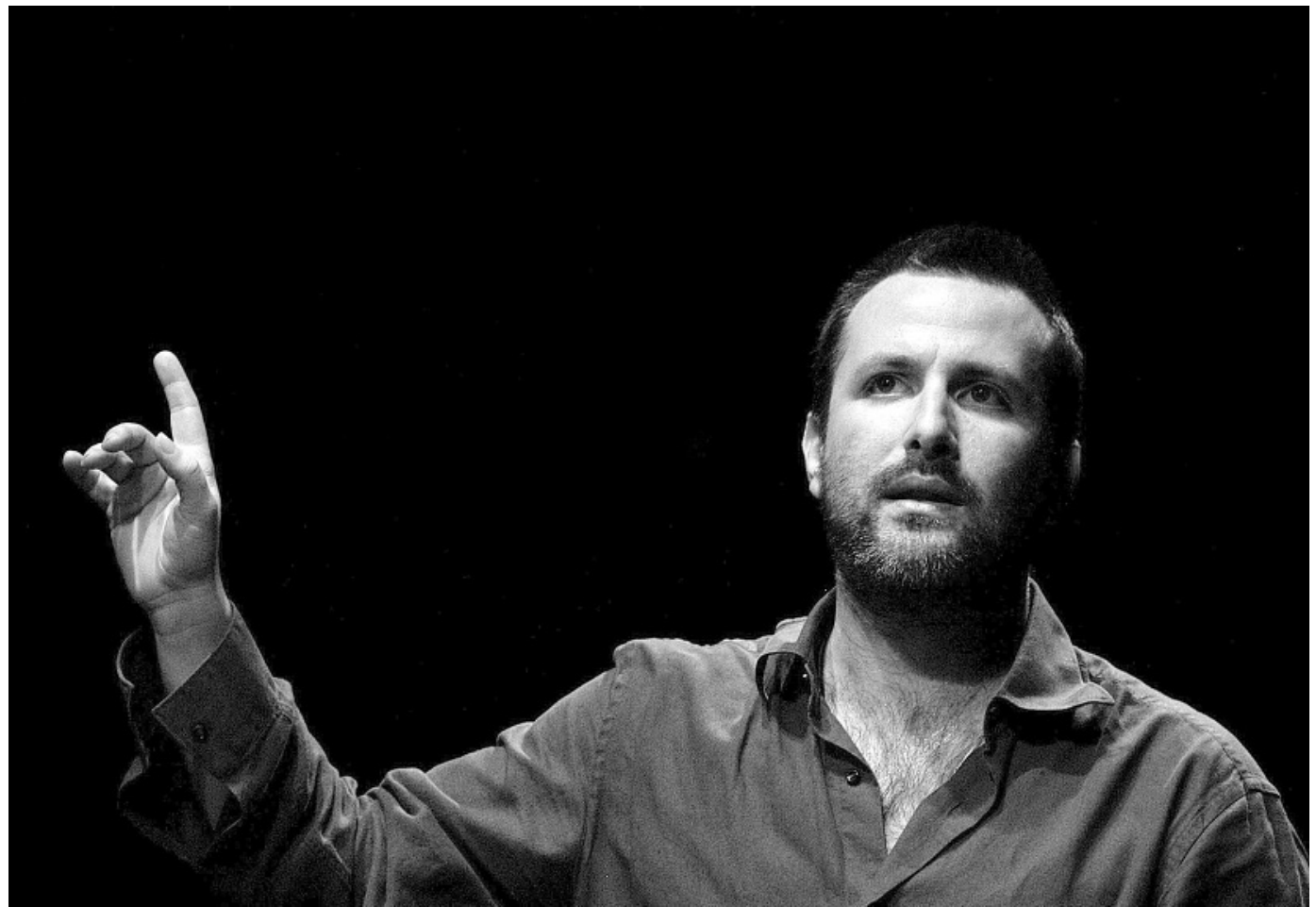

Ainda que tendo em conta o tema do presente colóquio, onde somos convidados a pensar sobre "os mais diversos modelos de representação e os mais distintos entendimentos das funções expressivas reservadas ao 'intérprete'", não consigo deixar de recuperar uma das mais extraordinárias experiências que tive enquanto espectador. Apesar de ter assistido a este espectáculo há já cerca de três anos, permanecem ainda vivas na minha memória as impressionantes imagens da cidade de Palermo a arder após um bombardeamento americano. E é de maneira assaz viva que também recordo os traços peculiares da família do pequeno Gioacchino: o Tio Cesare, o Umbertino, e todos os outros. Este superlativo espectáculo que lembro aqui é Maggio '43 (Maio 1943), escrito e interpretado pelo italiano Davide Enia, apresentado no Teatro Taborda, a convite dos Artistas Unidos e integrado na sua programação, em Maio de 2005.

Em palco, além de um músico (Giulio Barocchieri), o actor-autor Davide Enia era o único intérprete. Sozinho, narrava a história de Gioacchino, um rapazito siciliano que contava as desventuras pícaras da sua família e da sua cidade defronte da campa do seu falecido irmão. Narrava as dificuldades vividas numa Itália em plena
Segunda Guerra Mundial, os infatigáveis esforços da sua família para sobreviver e para arranjar dinheiro, os jogos ilícitos, a polícia fascista, os aviões americanos... Tudo isto era atravessado pela sua narração e interpretado por Davide Enia, sem nunca se levantar, por um segundo sequer, da sua cadeira. Sempre sentado, recorrendo somente aos recursos expressivos que os seus braços, face e voz Ihe providenciavam, compunha brilhantemente todos os "corpos" evocados em palco.

Assim, considerando o tema do presente colóquio tomo aqui este espectáculo como um ponto de partida para discutir o papel do corpo do actor no teatro narrativo e a importância da narração oral em alguma da criação teatral contemporânea em Portugal. Desde logo, a interpretação e o espectáculo de Enia incitam-nos - a nós, críticos de teatro - a questionar o que avaliar. Como se analisa um espectáculo que acontece, essencialmente, na mente do público? Com que critérios devemos nós analisar uma mise en oralité, treinados que estamos a ver antes de ouvir? Qual é o papel do corpo do intérprete nesta mise en bouche? Enfim, qual é a relação entre a figura do contador de histórias e a do actor? 


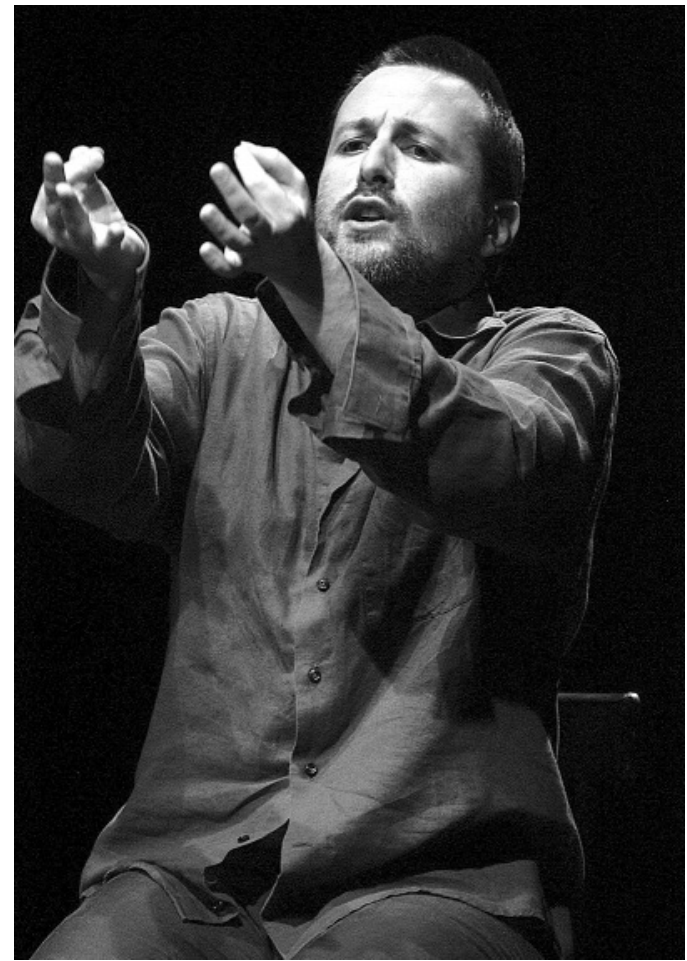

Será sensato começar por distinguir a figura do contador da do narrador (ou do récitant). De acordo com Patrice Pavis, o contador de histórias é:

[U]m artista que se situa no cruzamento de outras artes: sozinho em cena (quase sempre), narra a sua ou uma outra história, dirigindose directamente ao público, evocando acontecimentos através da fala e do gesto, interpretando uma ou várias personagens, mas voltando sempre a seu relato. (Pavis 1999: 69)

Deste modo, o objectivo desta figura será o de estabelecer um contacto directo com o público, "reatando os laços com a oralidade" (/bidem). E este é, com efeito, um dado importante: o estabelecimento de uma ligação mais próxima com o público permite que haja uma partilha do tempo do espectáculo: estão ambos no tempo da narração, ali e então, aqui e agora. Um outro dado relevante será que o foco do espectáculo transita da corporalidade do actor para a imaginação do espectador. 0 objectivo será, pois, deixar que o corpo do intérprete desapareça.

A fronteira entre o contador tradicional (o da tradição oral) e o contador-actor é muito ténue e na cena contemporânea há muitos focos de contaminação. De facto, muitos contadores recorrem a recursos teatrais, tais como microfones, luzes ou música e, por outro lado, e mais uma vez de acordo com Pavis: "a arte do contador de histórias renovou a prática teatral de nossos dias. Ela insere-se na corrente do teatro-narrativa, que dramatiza materiais não-dramáticos e casa perfeitamente a atuação e a narrativa" (Ibidem). E este era precisamente o caso de Maggio '43: a narrativa de Davide Enia é elaborada a partir de diferentes entrevistas realizadas a sobreviventes reais do bombardeamento de Palermo pela aviação aliada em 1943.

Se bem que Antoine Vitez tenha sido pioneiro nesta prática, no teatro ocidental, associamos facilmente o nome de Dario Fo, Antunes Filho ou Peter Brook a este tipo de cruzamento entre narração e teatro. Numa entrevista com Margaret Croyden, o encenador inglês explicava:

Qualquer tipo de narração oral é a mais poderosa corrente de vida que existe. [...] Para alcançar uma preocupação partilhada por todos e a todos os niveis, nada é mais poderoso do que a história. É por isso que, frequentemente, nos referimos a nós próprios como contadores de histórias. (Brook 2003: 173, tradução minha)

Nestes singelos apelos à simplicidade, encontramos facilmente a necessidade de redução do aparato teatral e uma forte ênfase dada à palavra. 0 teatro narrativo reivindica essa mesma essencialidade: alguém conta uma história a outrem. Não obstante este apelo, a ligação mais imediata e mais frutífera entre narração e teatro será aquela que se fizer ao teatro brechtiano e ao seu uso da narração e do narrador. As repercussões do modelo brechtiano no teatro ocidental serão porventura incalculáveis. No entanto, serão centrais para as noções de "epicização" de Peter Szondi, de "rapsodização" de Jean-Pierre Sarrazac ou mesmo para a de "pós-dramático" de Hans-Thies Lehman, onde a questão da narração se configura, entre outras, como uma maneira de superação ou reinvenção do modelo dramático. De uma maneira eloquente, Maria João Brilhante alude a esta cartografia da seguinte maneira:

0 que parece [...] permanecer incólume a toda a transformação vivida pela escrita de teatro e pelo teatro nestes últimos cinquenta anos é o papel central do acto de contar e as implicações do discurso narrativo na configuração do texto de teatro. Actualmente, podemos reconhecer sob ou apesar da recusa da fábula e sob ou apesar da recusa do drama [...] uma tendência [...]: o reencontro com o corpo enunciador do actor, com a sua capacidade de transformar sobre a cena esses textos, narrativos ou não [...]. Não se trata de um regresso
Maggio ' 43 , texto e enc. Davide Enia, 2005 (Davide Enia), [cortesia Artistas Unidos]. 
à apregoada prepotência do escritor e do texto, mas de recuperar após o império da semiótica teatral, da antropologia e da performance a dimensão performativa do acto de fala, a dimensão poética da criação de discursos para serem recriados pelo actor e intervirem no presente da acção teatral. (Brilhante 2002)

Embora possamos perseguir cada uma destas pistas, e com notórias vantagens para a presente reflexão, o que aqui desejo sublinhar são as relações entre o teatro e a narração oral e entre o actor e o contador de histórias. Se esta relação tem mais história, por exemplo, em França ou Inglaterra, onde o contar histórias é uma actividade profissional desde os anos sessenta/setenta (com contadores como Henry Gougaud, Bruno de la Salle, Pepito Mateo, Mary Medlicott ou, desde o início dos anos oitenta, Bem Haggarty, entre muitos outros), em Portugal somente pelos anos noventa pudemos testemunhar um surgimento de contadores profissionais. E, curiosamente, muitos vieram da prática teatral. Com efeito, o primeiro contador profissional que granjeou reputação enquanto tal terá sido António Fontinha, um ex-actor, que inspirou os passos de outros: Ângelo Torres (também actor), Horácio Santos, José Craveiro, entre muitos outros. No final dos anos noventa, a cidade de Beja tornar-se-á um importante pólo na narração oral em Portugal, sobretudo devido aos esforços de Cristina Taquelim e da Biblioteca Municipal de Beja, responsáveis pela organização do festival Palavras Andarilhas (primeira edição em 1999), onde se reúnem professores e educadores interessados em literatura infantil bem como contadores profissionais e outros vindos da tradição oral. Este evento ajudou a construir uma rede activa de narração oral profissional e, hoje em dia, são cada vez mais os actores que trocam ou que alternam a prática teatral com esta actividade.

Tendo este "mapa" em linha de conta, discutirei quatro espectáculos a que pudemos recentemente assistir em Lisboa. Os dois primeiros, não sendo exclusivamente produções nacionais, são suficientemente paradigmáticos do que aqui queremos apresentar e ajudam a uma reflexão sobre a contaminação entre as figuras do actor, do narrador e do contador de histórias na cena portuguesa. China, de William Yang, um fotógrafo-performer-contador de histórias australiano (de origem chinesa), foi apresentado no Museu do Oriente em Junho de 2008, integrado na programação do Alkantara Festival. Entre os anos de 1989 e 2005, Yang viajou por várias vezes entre a Austrália e a China e neste espectáculo evoca as memórias e os passos dessas viagens. A sua cativante arte de contador leva o público da Praça Tiananmen aos pequenos quartos onde foi dormindo, das salas de estar dos seus anfitriões até às mesas de restaurantes onde comeu, e das ruas e jardins que visitou às faces e poses daqueles que conheceu. Assim, de pé e ao centro do palco, Yang ia comentando as fotografias e os breves vídeos que eram projectados em dois grandes ecrãs, adicionando-Ihes curtos relatos. 0 tom era o de uma apresentação de fotografias de férias: num ritmo calmo e compassado, ancorando a narrativa na aleatoriedade da projecção das imagens. Por vezes, depois de comentar alguma imagem ou alguma sequência de imagens, virava tranquilamente as costas ao público, olhando para os ecrãs e convidando-nos a melhor observar as fotos. No final, era perceptivel a fusão entre o narrador e a cultura que narrava, a chinesa. Se no início alguns comentários eram de espanto ou destacavam a estranheza, no final da narração Yang já não estava a lidar com a alteridade ou com o exótico. No final abraçava a sua cultura perdida - e com isto o seu "corpo perdido". De certa maneira, o corpo de Yang dissolvia-se na China: no pais e na cultura, mas também em China, o espectáculo. 0 corpo do recatado contador de histórias que calmamente narrava as suas viagens, contrastava com o exultante e entusiasmado corpo do viajante, projectado nos ecrãs. Desta maneira, a figura do narrador desaparecia para dar lugar ao corpo virtual que habitava as imagens projectadas.

Na mesma edição do Alkantara Festival, um outro espectáculo lidava com memórias de viagens: Yesterday's Man, de Rahib Mroué, Tiago Rodrigues e Tony Chakar. Apresentado no Teatro da Politécnica, este espectáculo enredava o espectador numa teia devedora dos labirintos borgesianos, das conspirações de Eco ou da poética da coincidência de Paul Auster: Tiago Rodrigues, o intérprete, permanecendo sempre sentado a uma secretária iluminada por um pequeno candeeiro, sorvendo ocasionalmente chá de um termos que retirou de uma mochila que guardava a seus pés, narrava as peripécias de uma das suas viagens a Beirute. Num ecrã, eram projectadas fotos e mapas, ajudando à progressão da narrativa. Subitamente, aquilo que parecia ser a história de uma viagem vai acabar por ser o testemunho da passagem do tempo e das brutais mudanças impostas a uma cidade pelas guerras e pela erosão da memória. Tiago Rodrigues, procurando um edificio que descobrira num mapa, vai encontrar outros Tiagos Rodrigues, enclausurados no tempo e no espaço, todos à procura de espaços que ou já não existiam ou 


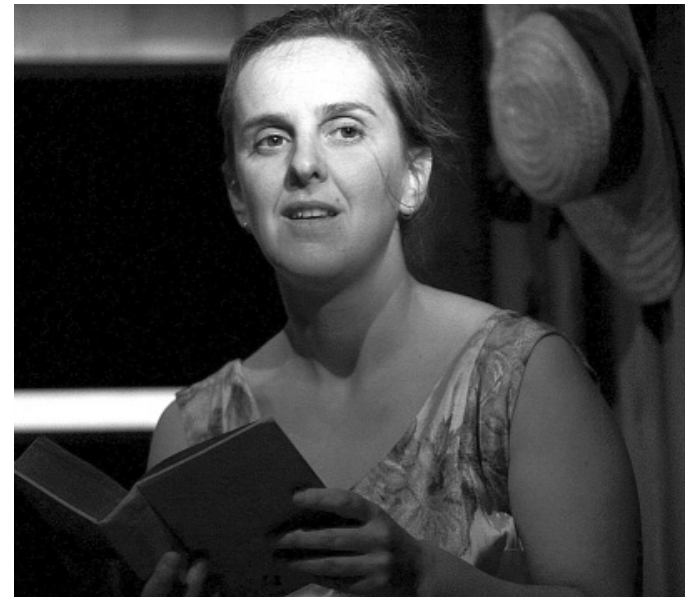

ainda não tinham sido construídos. A justaposição destas histórias denunciava as mudanças ocorridas em Beirute e na própria percepção do narrador acerca de si próprio. Mais uma vez, no final do espectáculo, testemunhávamos o desaparecimento do corpo do narrador na cidade. Esta metáfora era efectivamente tornada explícita: a última imagem projectada era mesmo uma fotografia de Rodrigues a suavemente desaparecer nas ruínas de Beirute...

Apesar da singularidade destes dois espectáculos, na criação teatral portuguesa contemporânea, talvez seja o Teatro Meridional a trabalhar de uma maneira mais consistente o universo da narração oral. Com efeito, esta é precisamente uma das quatro linhas de actuação artística do colectivo: 1) encenação de textos originais; 2) encenação e adaptação de textos fundamentais da dramaturgia universal; 3) criação de espectáculos onde a palavra não é a principal forma de comunicação cénica; 4) "a criação de novas dramaturgias baseadas em adaptações de textos não teatrais (com relevo para a ligação ao universo da lusofonia, procurando fazer da língua portuguesa um encontro com a sua própria história)" (cf.

http://www.teatromeridional.net). E este é precisamente o caso de Cabo Verde (Setembro de 2007): fazendo parte de um projecto em curso intitulado "Contos em viagem", o espectáculo é dedicado a Cabo Verde (depois de em 2006 ter havido um espectáculo dedicado ao Brasil). Baseado em diferentes textos, poemas e histórias, uma actriz (Carla Galvão) e um músico (Fernando Mota) convocavam os ambientes, os cheiros, a atmosfera, as pessoas, os mitos e, muito concretamente, uma dimensão cerimonial entre o público e o palco, ecoando a sincronicidade da narração de um contador de histórias, estabelecendo um contacto directo com os espectadores e fazendo da comunicabilidade o pilar primeiro do espectáculo. Apesar de recorrer a bastantes artifícios teatrais - tal como o (magnífico) espaço cénico de Marta Carreiras, construído como um cais ou uma ilha, pleno de objectos do quotidiano, tais como baldes, pedaços de madeira, mangueiras, etc. - , o trabalho de Galvão construíase assumidamente como o de um contador de histórias. Não obstante a absoluta expressividade da interpretação da actriz, o seu corpo desaparecia na dimensão poética da sua narração.

Este processo é similar ao que acontecia com On the road ou A hora do arco-íris, texto de Carlos J. Pessoa, encenado por Ana Palma e interpretado por Maria João

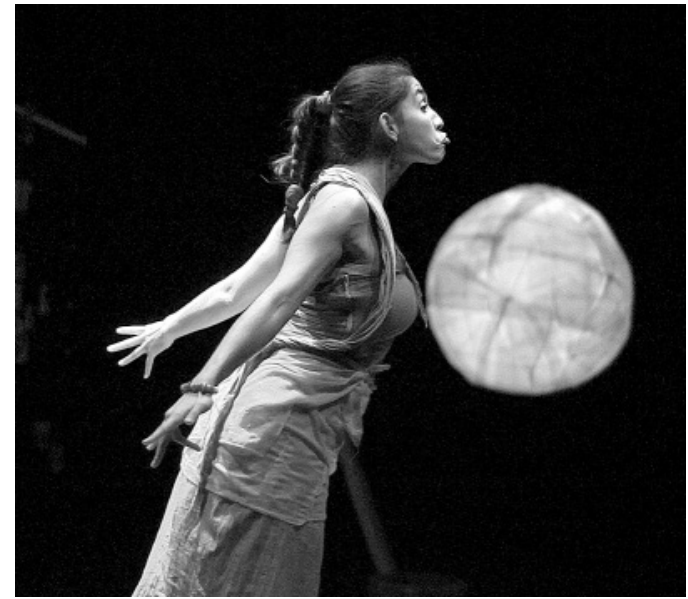

Vicente, estreado em Abril de 2008. Contudo, aqui, a figura do narrador e do contador de histórias não está claramente presente. Trata-se de um monólogo de uma mulher que viaja entre Sagres, no Algarve, e Pulo do Lobo, no Alentejo, numa auto-caravana. E esta epopeia lírica é o pretexto para que no relato se exorcizem algumas das preocupações da sua geração sobre a vida, sobre o amor e sobre a política. 0 espectáculo, alicerçado numa plasticidade (de Sérgio Loureiro), num ambiente sonoro (de Daniel Cervantes) e num desenho de luz (de Miguel Cruz) de belíssima composição, erguia-se como um relato poético das viagens que a protagonista encetava: a viagem real pela paisagem, mas também a viagem interior. Esta mulher visitava velhos amigos e ia resolvendo os problemas que se the deparavam, mas, sobretudo, confrontava-se com os seus próprios pensamentos. A poesia e a nostalgia do texto de J. Pessoa lutavam com a alegria e a vivacidade da interpretação de Maria João Vicente. Esta combinava na perfeição um registo mais evocativo e teatral com um contacto directo com o público, criando a ilusão de que o espectador partilhava por momentos o seu tempo de representação. Mas, subitamente, o registo do espectáculo mudava de novo para um registo mais contemplativo. 0 resultado era bastante impressionante.

Ora combinando técnicas da narração oral, ora enfatizando o uso da linguagem, todos estes espectáculos lidavam com a palavra antes de olharem para o corpo. A mise en oralité presente em todas estas criações permitia ao corpo desaparecer em palco e tornar-se (aparentemente) um simples veículo para a palavra. Contudo, é claro que este número de desaparecimento apenas vem acentuar a importância do corpo no acto de contar e de representar.

\section{Referências bibliográficas}

BRILHANTE, Maria João, (2002), "Um teatro que sabe o que significa narrar", Revista Semear, n 7, Rio de Janeiro, Cátedra Padre António Vieira de Estudos Portugueses, pp.47-73 (também em www.letras.puc-

rio.br/catedra/revista/7Sem_05.html, acedido em Setembro de 2008) BR00K, Peter / Croyden, Margaret (2003), Conversations with Peter Brook (1970-2000), New York \& London, Faber and Faber.

PAVIS, Patrice (1999), Dicionário de teatro, trad. sob direcção de J. Guinsburg e Maria Lúcia Pereira, S. Paulo, Editora Perspectiva.
On the road ou A hora do arco-iris, de Carlos J. Pessoa, enc. Ana Palma, Teatro da Garagem, 2008 (Maria João Vicente), fot. Marisa Cardoso.

Contos em viagem: Cabo Verde, selecção de textos de Natália Luiza, enc. Miguel Seabra, Teatro Meridional, 2007 (Carla Galvão), fot. Patricia Poção. 